\section{A Highly Efficient In Vitro Cranberry Regeneration System Using Leaf Explants}

\author{
Luping Qu ${ }^{1}$, James Polashock ${ }^{2}$, and Nicholi Vorsa ${ }^{3}$ \\ Blueberry and Cranberry Research Center, Rutgers University, Chatsworth, \\ NJ 08019
}

Additional index words. shoot organogenesis, thidiazuron, NAA, 2ip, Vaccinium macrocarpon

Abstract. A very efficient adventitious regeneration (shoot organogenesis) system for cranberry (Vaccinium macrocarpon Ait.) leaves was developed. A basal medium consisting of Anderson's rhododendron salts and Murashige and Skoog's (MS) organics, supplemented with 10.0 $\mu \mathrm{M}$ thidiazuron (TDZ) and $5.0 \mu \mathrm{M} 2 \mathrm{ip}$, was effective for adventitious regeneration from leaves for the five cranberry cultivars tested: 'Early Black', 'Pilgrim', 'Stevens', 'Ben Lear', and 'No. 35'. Parameters examined included: 1) varying combinations of three plant growth regulators (TDZ, 2ip, and NAA); 2) explant orientation (adaxial vs. abaxial side in contact with the medium); and 3 ) leaf position relative to the apical meristem from the source plant. Cultivars varied in regeneration frequency, but cultivar $\times$ growth regulator interaction was nonsignificant. With optimal treatment conditions, regeneration occurred on more than $95 \%$ of the explants, with 'Early Black' and 'Pilgrim' producing as many as 100 shoot meristems per explant. At all concentrations tested, NAA (as low as $0.1 \mu \mathrm{M}$ ) increased callus formation and significantly reduced regeneration. Emerging adventitious shoots were always observed on the adaxial side of the leaves regardless of explant orientation on the medium. Regeneration was much greater when the abaxial side was in contact with the medium, and was not related to leaf position on the source plants. Elongation of adventitious shoots began $\approx 2$ weeks after transfer to the basal medium without growth regulators. Cuttings of elongated shoots rooted $100 \%$ both in vitro in the basal medium and ex vitro in shredded sphagnum moss. The high regeneration efficiency achieved by using this system will be very useful in the application of techniques, such as Agrobacterium- and particle bombardment-mediated transformation. Chemical names used: 1-phenyl-3-(1,2,3-thiadiazol-5-yl) urea (thidiazuron, TDZ); $N^{6}-(\gamma-\gamma-$ dimethyallylamino) purine (2ip); $\alpha$-naphthaleneacetic acid (NAA).

The American cranberry is a native North American fruit crop with current annual production of $\approx 249,000 \mathrm{t}$ (New Jersey Agriculture Statistics Service, 1997). Cranberry fruit is utilized mostly for juices, but also for a variety of other products. Cranberry has been identified as having medicinal properties, namely antiadhesion effects on Escherichia coli in the urinary tract (Ahuja et al., 1998; Howell et al., 1998; Ofek et al., 1991).

Cranberries have been cultivated on a large scale since the mid-1800s and many of the cultivars today are wild selections made over 100 years ago. Several hybrid varieties from controlled crosses were released between the mid-1950s and 1970 (Eck, 1990). The American cranberry is a woody perennial requiring a chilling period for growth and flowering and having a lengthy juvenile stage, which retards progress in breeding and selection. Breeding programs largely aimed at improving horticul-

Received for publication 7 June 1999. Accepted for publication 29 Dec. 1999. The cost of publishing this paper was defrayed in part by the payment of page charges. Under postal regulations, this paper therefore must be hereby marked advertisement solely to indicate this fact.

${ }^{1}$ Postdoctoral Research Associate.

${ }^{2}$ Assistant Research Director.

${ }^{3}$ Professor and Director. To whom reprint requests should be addressed. E-mail address: vorsa@aesop.rutgers.edu tural traits are located in Wisconsin and New Jersey.

Biotechnology for crop improvement is a useful system for complementing breeding programs and offers the opportunity for interspecies gene transfer and for the direct introduction of useful genes into elite genotypes. Cranberry biotechnology is still in its infancy. Ideally, a genetic transformation system for cranberry should have: 1) a method for adventitious plant regeneration from somatic tissues of elite genotypes; 2) a reliable method for gene transfer and integration into the cranberry genome; and 3) a system to select transformed plants. One limiting factor thus far has been the lack of an efficient plant regeneration system.

Serres et al. (1992) produced transgenic cranberry plants by particle bombardment of regenerating stem tissue, followed by kanamycin selection, utilizing expression of an integrated NPTII gene. Although successful, this system appears to generate a relatively low frequency $(0.15 \%)$ of recovered transclones. Furthermore, the stems of cranberry, particularly from plants already grown in axenic culture, are slender and therefore provide a limited target area for bombardment.

Leaves typically offer a larger target area for bombardment and are often the organ of choice for Agrobacterium- and particle bombardment-mediated transformation. Thus, regeneration from leaves would be highly desirable for cranberry transformation efforts. The process of regeneration from leaves can be divided into the following steps: 1) formation of viable adventitious buds on the explant; 2) elongation of the buds into shoots; and 3) rooting of the shoots to form whole plants. Marcotrigiano et al. (1996) examined the effects of two cultivars and various NAA/TDZ combinations on regeneration from cranberry leaves. However, efficiency using this system was low, with the lack of elongation of the adventitious shoots being a key problem.

The purpose of this study was to identify factors, including hormonal, physical and genetic, that influence cranberry regeneration, and to optimize all three steps using cranberry leaves. First, in order to identify hormonal factors influencing regeneration, various plant growth regulator (including cytokinin and auxin) combinations were tried. Second, the effects of other factors, including explant orientation on the medium, genotype (cultivars), and source leaf position (age) on regeneration were investigated.

\section{Materials and Methods}

Plantmaterials, initiation andmaintenance of in vitro shoots. The leaves of cranberry cultivars Stevens (ST), Early Black (EB), Pilgrim (PI), Ben Lear (BL), and No. 35 were used. All cultivars were verified by DNA fingerprinting using randomly amplified polymorphic DNA (RAPDs) (Polashock and Vorsa, unpublished data). To establish in vitro shoot cultures as a source of leaf explants, shoots were harvested from greenhouse-grown plants, defoliated, and surface-disinfected by washing for $30 \mathrm{~s}$ in $70 \%$ ethanol, followed by 10 min in $20 \%$ commercial bleach (sodium hypochlorite). Sterilized water was used for three 10-min washes to remove residual bleach. Stem sections with two to four nodes were cultured in GA7 boxes (Magenta Corp., Chicago) containing $\approx 60 \mathrm{~mL}$ of basal medium [Anderson's major and micro salts (Anderson, 1975), MS organics (Murashige and Skoog, 1962), and $2 \%$ sucrose]. The $\mathrm{pH}$ of the medium was adjusted to 5.3 with a solution of potassium hydroxide $(0.5 \mathrm{~N})$ before autoclaving $\left(121^{\circ} \mathrm{C}, 15 \mathrm{~min}\right)$ and solidified with $5 \mathrm{~g} \cdot \mathrm{L}^{-1}$ Agargel (Sigma Chemical Co., St. Louis). Culture chambers were maintained at $25 \pm 1$ ${ }^{\circ} \mathrm{C}$ and a 16-h daily photoperiod provided by cool-white fluorescent tubes at $40 \mu \mathrm{mol} \cdot \mathrm{m}^{-2} \cdot \mathrm{s}^{-1}$. Subcultures were made at 2- to 4-month intervals. In all of the regeneration experiments reported in this study, explants were maintained under the same conditions.

Regeneration medium. The regeneration medium tested consisted of the basal medium for shoot culture supplemented with a plant growth regulator or growth regulator combination. The growth regulators utilized were TDZ, 2ip and NAA. The growth regulator solutions were filter-sterilized and added after the basal medium was autoclaved and cooled to $40-50{ }^{\circ} \mathrm{C}$. Specific combinations of the growth regulators tested for regeneration are detailed below. 
Culture methods and experimental design. Leaves for the regeneration experiments were collected from in vitro cultured plants that were 4 weeks to 3 months old after initiation. All manipulations of the leaves were performed on sterile filter paper saturated with the basal medium to prevent desiccation. Leaves were removed from the shoots by cutting at the petiole base with a scalpel. A longitudinal cut close to or on the midrib separated the leaf into two halves, which are referred to as "explant(s)." For regeneration experiments, explants were transferred to 100 $\times 16$-mm disposable petri plates containing $\approx 25 \mathrm{~mL}$ of the appropriate medium and the plate was sealed along the rim with one layer of Parafilm ${ }^{\circledast}$ (American National Can, Greenwich, Conn.). For all regeneration experiments, the plates were kept in the dark for $2 \mathrm{~d}$ (wrapped in aluminum foil) immediately after transfer to the appropriate medium. Four experiments were conducted as detailed below.

Expt. 1. Effects of NAA and varying levels of TDZ and 2ip on adventitious shoot regeneration. Six to eight fully or nearly fully expanded leaves nearest the apical meristem from 3-month-old in vitro ST plants were used. A factorial design was employed with factors 2ip (two levels, 5.0 or $10.0 \mu \mathrm{M}$ ), TDZ (three levels, 1.0, 5.0, or $10.0 \mu \mathrm{M}$ ), and NAA (three levels, 0.0, 0.5, or $1.0 \mu \mathrm{M}$ ). Four explants were placed in each plate with random sides (adaxial or abaxial) in contact with the medium. Because of slight curving of the leaves (toward the abaxial side), explants with adaxial side down maintained better contact with the medium than those with abaxial side down. This test was replicated four times (four plates for each treatment). Placement of the plates in the incubator was randomized across treatments.

Expt. 2. Effects of cultivar and explant orientation on regeneration on basal medium supplemented with $10.0 \mu_{\mathrm{M} \mathrm{TDZ}}$ and $5.0 \mu_{\mathrm{M}}$ 2ip. Explants from $\approx 4$-week-old in vitro ST, EB, PI, BL, and No. 35 plants were used. Leaves were collected from the shoot apex (excluding the apical leaves under $1.5 \times 2 \mathrm{~mm}$ ) to about the 6th leaf position. Between 40 and 70 explants of each cultivar were placed on two or three plates with abaxial side in contact with the medium.

After $15 \mathrm{~d}$ culture on basal medium with $10.0 \mu \mathrm{M} \mathrm{TDZ}$ and $5.0 \mu \mathrm{M} 2 \mathrm{ip}$, the explants were transferred to a medium with $1.0 \mu \mathrm{M}$ TDZ and $10.0 \mu \mathrm{M} 2 \mathrm{ip}$. An additional plate of PI was kept on the medium with $10.0 \mu \mathrm{M}$ TDZ and $5.0 \mu \mathrm{M}$ 2ip. As a secondary treatment for ST and EB, about the same number of explants were placed with the adaxial side in contact with the medium.

Expt. 3. Leaf position $\times$ cultivar effects on regeneration (10.0 $\mu_{M} \mathrm{TDZ}$ and $\left.5.0 \mu_{M} 2 \mathrm{ip}\right)$. A five cultivar (ST, EB, PI, BL, and No. 35) $\times$ ten leaf position (position of source leaves relative to apical meristem) factorial design was used. Leaves from actively growing $\approx 2$-month-old in vitro plants having 15 or more leaves were used. Leaf sizes among shoots were similar $(\approx 2.5 \times 5 \mathrm{~mm})$. Generally, basal leaves were slightly larger than the more apical ones. Explants of 10 leaves (excluding the apical leaves under $1.3 \times 2.5 \mathrm{~mm}$ ) from the distal part of the shoot were placed in order in the plates with the abaxial side in contact with the medium. Each plate contained all five cultivars in random order. The experiment was repeated five times. After $15 \mathrm{~d}$ culture on the medium with $10.0 \mu_{\mathrm{M}} \mathrm{TDZ}$ and 5.0 $\mu_{\mathrm{M}} 2 \mathrm{ip}$, the explants were transferred to fresh medium with $1.0 \mu \mathrm{M}$ TDZ and $10.0 \mu \mathrm{M} 2 \mathrm{ip}$.

Expt. 4. Evaluation of cultivar $\times$ medium growth regulator interactions. A four cultivar $(\mathrm{ST}, \mathrm{EB}, \mathrm{PI}$, and $\mathrm{BL}) \times$ nine growth regulator factorial design was employed. Leaves from the 8th position (from the apical meristem) and above (excluding the apical leaves under $1.3 \times 2.5 \mathrm{~mm}$ ) of 1 -month-old in vitro plants were used. Nine growth regulator combinations were tested with TDZ: $2 \mathrm{ip}$ : NAA (in $\mu \mathrm{M})$ at the following concentrations-10:10:0, 10:5:1, 10:5:0.5, 10:5:0.1, 10:5:0, 10:0:1, 10:0:0, 5:10:0, and 5:5:0. The 10:0:1 treatment represented the best growth regulator combination used by Marcotrigiano et al. (1996). Explants were placed on the plates with the abaxial side in contact with the medium. Each plate contained all four cultivars ( $\approx 10$ explants for each). The experiment was repeated three times, with the plates randomized within a replication.

Elongation. The basal medium without growth regulators was the elongation medium. After $\approx 4$ weeks on the $1.0 \mu \mathrm{M}$ TDZ and $10.0 \mu \mathrm{M}$ 2ip regeneration medium, some regenerating explants from Expt. 2 (26 EB, 22 PI, and 20 ST) and all those from Expt. 3 were transferred to Magenta GA7 boxes containing $\approx 60 \mathrm{~mL}$ of the basal medium. About 10 Expt. 2 and 20 Expt. 3 explants were placed in each box. The remainder of the Expt. 2 explants were kept on the regeneration medium for an additional 3 months, and were then transferred to the basal medium.

Rooting. Elongated shoots (>1.5 cm long) were cut at the base and were rooted in the basal medium in Magenta GA7 boxes, and in shredded sphagnum moss in small $(5 \times 5-\mathrm{cm}$ square) plastic pots. Twenty cuttings of each cultivar were planted in each rooting medium. The GA7 boxes were wrapped along the rim with one layer of Parafilm ${ }^{\circledR}$ and the pots were loosely covered with plastic wrap.

Data collection and statistical analysis. Regeneration data were collected 22-28 d after explant cultures were initiated. Nondestructive counts of shoot meristems $(\geq 0.5$ $\mathrm{mm}$ long, surrounded by a few small leaves) were made using a dissecting microscope with the plate cover in place. When exact counts were difficult to obtain, which was often the case due to extensive shoot meristem formation on an explant, the number was estimated to the nearest five.

Elongation data were collected $25 \mathrm{~d}$ after the explants were transferred to the basal medium. Shoots with expanded internodes (>1 cm long) were categorized as elongated. Rooting results were checked a week after the cuttings were planted, and daily, until all of them were rooted.

Data were subjected to variance analysis using the general linear model procedure of the Statistical Analysis System (SAS Institute, Cary, N.C.)

\section{Results}

Expt. 1. Effects of NAA and varying levels of TDZ and 2ip on adventitious shoot regeneration. Callus development occurred only on the adaxial side. On medium lacking NAA, callus formation on the explants was much reduced and the callus was green. Callus formation was rapid on medium with NAA, and the callus was initially white or light green. On medium lacking NAA, explants with the abaxial side down tended to curl (after $8 \mathrm{~d}$ ) toward the abaxial side, resulting in explants lying on their sides on the medium. In contrast, explants with the adaxial side on the medium curled upward. Curling was much less pronounced on medium with NAA, with explants remaining relatively flat.

Emergence of adventitious shoots from the adaxial side of the explants was observed after $\approx 12 \mathrm{~d}$ in culture on medium lacking NAA, while the explants on the NAA-containing medium appeared more swollen, and had more vigorous callus growth with no visible regeneration. Regeneration was first noted at $15-16 \mathrm{~d}$ in a few explants on the medium containing $0.5 \mu \mathrm{M}$ NAA. After $\approx 4$ weeks in culture, the average explant size on the medium containing NAA was about three times as large as that on NAA-free medium (Fig. 1A).

In explants on the NAA-free medium, shoot meristems initially emerged from the tissue closest to the cut surface and gradually spread toward the leaf margin. Regeneration was always observed on the adaxial side regardless of the hormonal treatment or initial leaf orientation (Fig. 1B).

There was a significant inhibitory effect of NAA (contingency $-\chi^{2}, P \leq 0.001$ ) on the frequency of adventitious shoots regeneration (Table 1). After $28 \mathrm{~d}$ in culture, regeneration had occurred on $97 \%$ of the explants placed on the NAA-free medium vs. $4.2 \%$ of those on the NAA-containing medium. On the NAA-free medium, 5.0 and $10.0 \mu \mathrm{M}$ TDZ were equally effective, and both were more effective than $1.0 \mu \mathrm{M}$. The difference between 5.0 and 10.0 $\mu \mathrm{M} 2 \mathrm{ip}$ levels within any TDZ level was nonsignificant.

Table 1. Adventitious shoot regeneration from cranberry cultivar Stevens leaves on medium containing varying levels of TDZ, 2ip, and NAA.

\begin{tabular}{lccc}
\hline & \multicolumn{3}{c}{$\begin{array}{c}\text { Mean no. shoot meristems } \\
\text { per explant }\end{array}$} \\
\cline { 2 - 4 } TDZ : 2ip & \multicolumn{3}{c}{ NAA $(\mu \mathrm{M})$} \\
\cline { 2 - 4 }$(\mu \mathrm{M})$ & $9.2 \mathrm{a}$ & 0.5 & 1.0 \\
\hline $10: 10$ & $11.3 \mathrm{a}$ & $<1$ & 0 \\
$10: 5$ & $10.4 \mathrm{a}$ & 0 & 0 \\
$5: 10$ & $10.9 \mathrm{a}$ & 0 & 0 \\
$5: 5$ & $5.9 \mathrm{~b}$ & 0 & 0 \\
$1: 10$ & $5.4 \mathrm{~b}$ & 0 & 0 \\
$1: 5$ & 8.9 & $<1$ & 0 \\
Mean & $0^{\mathrm{y}}$ & 0 & 0 \\
\hline
\end{tabular}

${ }^{\mathrm{z}}$ Number of explants per treatment 14-16.

yean separation within column by LSD, $P \leq 0.01$. 
A
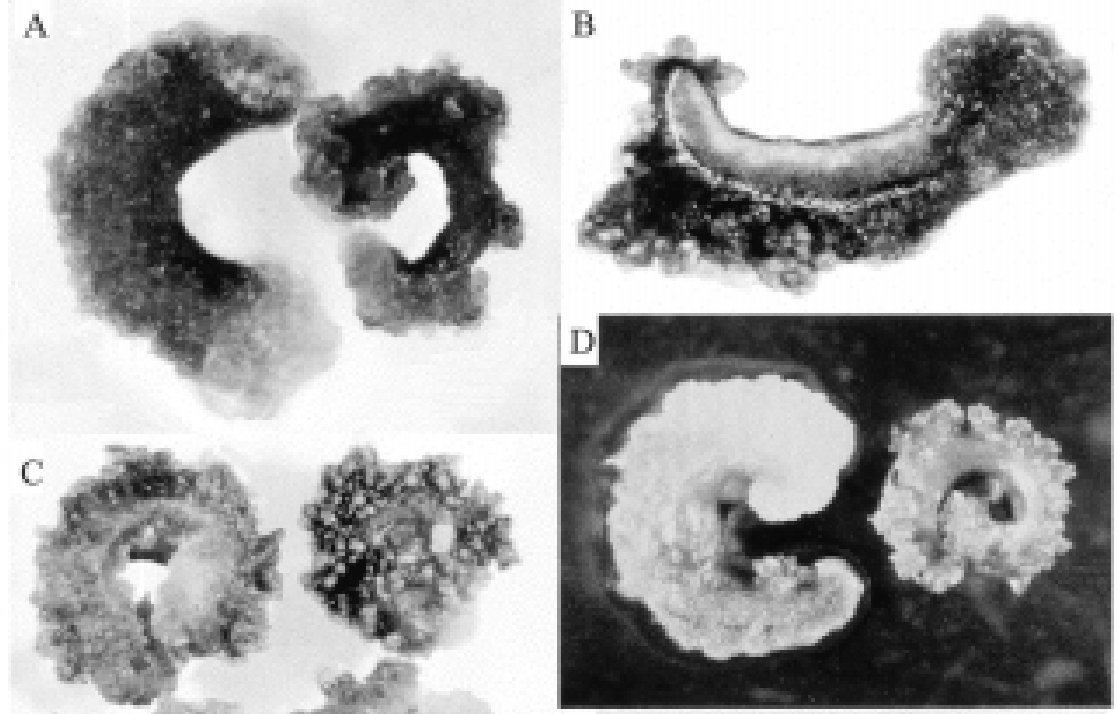

F

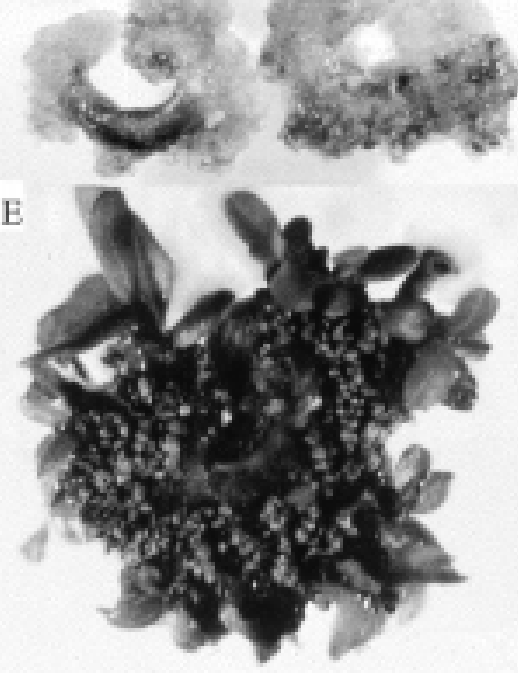

Table 2. Effect of cranberry genotype on induction of shoot meristems and their elongation. Abaxial surface in contact with the regeneration medium (TDZ $10.0 \mu \mathrm{M}: 2$ ip $5.0 \mu \mathrm{M}$ ).

\begin{tabular}{lccc}
\hline Genotype & $\begin{array}{c}\text { No. of } \\
\text { explants }\end{array}$ & $\begin{array}{c}\text { Mean no. } \\
\text { of shoot } \\
\text { meristems/ } \\
\text { explant }\end{array}$ & $\begin{array}{c}\text { Mean no. of } \\
\text { elongated shoot } \\
\text { meristems/ } \\
\text { explant }^{\mathrm{z}}\end{array}$ \\
\hline Pilgrim & 55 & $31.7 \mathrm{a}$ & $9.7 \mathrm{a}$ \\
Early Black & 52 & $30.4 \mathrm{a}$ & $10.2 \mathrm{a}$ \\
Stevens & 61 & $13.1 \mathrm{~b}$ & $3.5 \mathrm{~b}$ \\
Ben Lear & 51 & $10.3 \mathrm{~b}$ & --- \\
No.35 & 45 & $5.4 \mathrm{c}$ & --- \\
\hline
\end{tabular}

${ }^{2}$ Mean separation within columns by LSD, $P \leq 0.01$.

those with adaxial sides up for both cultivars tested [EB 30.4 (up) vs. 12.3 (down) and ST 13.1 (up) vs. 4.1 (down), shoot meristems/ explant, $\approx 50$ explants/treatment].

Expt. 3. Leaf position $\times$ cultivar effects on regeneration (10.0 $\mu_{M} \mathrm{TDZ}$ and $5.0 \mu_{\mathrm{M}} 2 \mathrm{ip}$ ). Shoot meristems appeared 1 to $2 \mathrm{~d}$ earlier on the younger (more apical) leaves across all cultivars. However, the effect of leaf position on source plants was not significant within cultivars, nor was there a significant cultivar by leaf position interaction (Table 3 ). As in Expt. 2 (data not shown), EB and PI produced significantly more adventitious shoots than did the other three cultivars. However, BL performed significantly better than did ST in this experiment. There were no significant differences between ST and No. 35 .

Expt. 4. Evaluation of cultivar $\times$ medium growth regulator interactions. Vigorous callus formation and reduced shoot formation were found across all cultivars in all growth regulator combinations containing NAA, especially at the two higher $(0.5$ and $1.0 \mu \mathrm{M})$ levels. Initial shoot meristem regeneration on the 0.5 and $1.0 \mu \mathrm{M}$ NAA medium was away from the cut surface and often occurred near the leaf margin (Fig. 1D). As in Expt. 1, callus formation on all NAA-free medium was minimal, and there were no obvious differences between the remaining growth regulator combinations. Significant regeneration differences among treatments were found, and cultivar $\times$ treatment interaction was nonsignificant (Fig. 2).

Elongation. No elongation of shoot meristems was observed when the explants were maintained on the regeneration medium. Some were kept on the medium containing $10.0 \mu \mathrm{M}$ TDZ and $5.0 \mu \mathrm{M} 2 \mathrm{ip}$ for more than 4 months with one transfer after culture initiation. Once explants were transferred to the basal medium, however, elongation occurred in $\approx 2$ weeks (Fig. 1E). In explants maintained on the medium supplemented with $1.0 \mu \mathrm{M}$ TDZ and 10.0 $\mu_{\mathrm{M}} 2 \mathrm{ip}$, expansion of leaves occurred on some shoot meristems after $\approx 25 \mathrm{~d}$ and some leaves gradually turned hyperhydric. Even after 3 months, shoot elongation was not observed on the $1.0 \mu \mathrm{M}$ TDZ, $10.0 \mu \mathrm{M} 2 \mathrm{ip}$, and $0 \mu \mathrm{M}$ NAA medium.

The shoot meristem initiation process continued after the explants were transferred to the elongation medium. Some EB and PI explants that were initially about half-covered with adventitious shoot meristems when the 
Table 3. Anaylsis of variance of effects of cranberry cultivar and leaf position on source plants on adventitious shoot formation (Expt. 3).

\begin{tabular}{lccc}
\hline \hline Variable & df & $\begin{array}{c}\text { No. of shoot } \\
\text { meristems }\end{array}$ & $\begin{array}{r}\text { No. of elongated } \\
\text { shoot meristems }\end{array}$ \\
\hline Genotype $(\mathrm{G})$ & 4 & $21132^{* * * *}$ & $1225^{* * *}$ \\
Leaf (L) & 9 & $459^{\text {Ns }}$ & $36^{\text {Ns }}$ \\
$\mathrm{G} \times \mathrm{L}$ & 36 & $225^{\mathrm{Ns}}$ & $28^{\mathrm{Ns}}$ \\
Error & 19 & 338 & \\
Ns, ${ }^{* * * *}$ Nonsignificant or significant at $P \leq 0.0001$. &
\end{tabular}

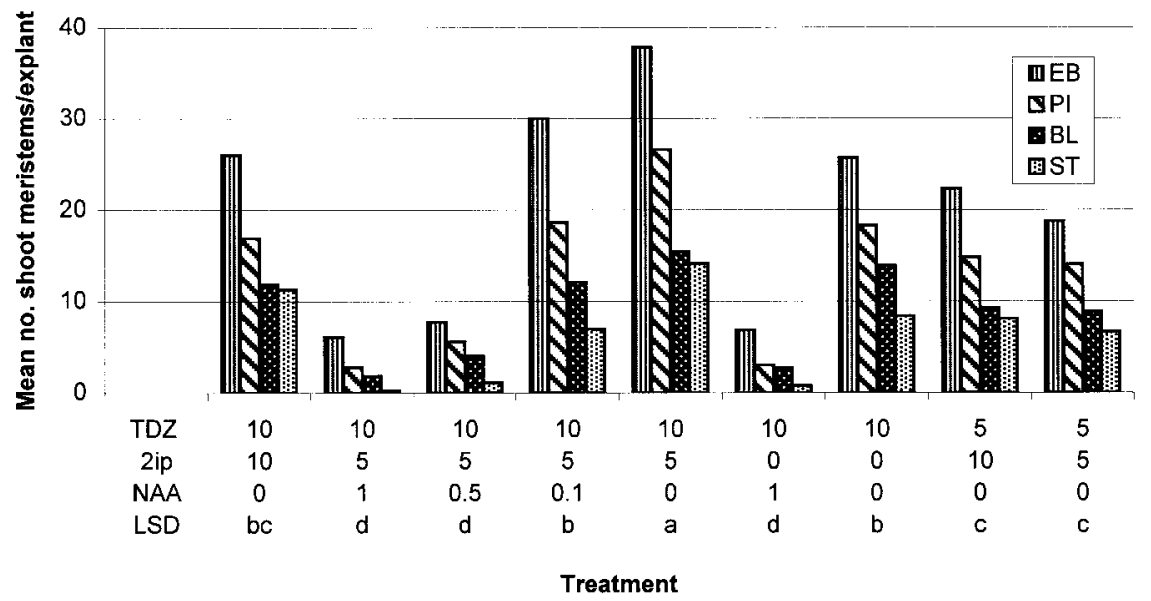

Fig. 2. Effects of genotype and growth regulator combinations on shoot meristem regeneration from cranberry leaves. Data were collected $25 \mathrm{~d}$ after culture initiation. Separation of treatment means by LSD, $P \leq 0.05$.

data were collected, continued to produce shoot meristems, and these almost covered the whole explant after $\approx 2$ weeks on the elongation medium (Fig. 1E). For explants transferred to the elongation medium (after $\approx 40 \mathrm{~d}$ on the regeneration medium), elongation was observed $\approx 2$ weeks later. Initial elongation appeared to be more from apical meristem activity than from elongation of the internodes. Shoot meristems, which were larger and closer to the side in contact with the medium, appeared to elongate more readily (Fig. 1E). Meristems continued to elongate for several months. About 40 shoots had elongated on some EB and PI explants after 3 months on the elongation medium (Fig. $1 \mathrm{~F}$ ), and appeared phenotypically normal. After $25 \mathrm{~d}$ in culture on the elongation medium, the largest shoots had reached $\approx 3 \mathrm{~cm}$ in height. Explants with more regenerated shoot meristems generally produced more elongated shoots (Table 2). Additional shoot meristems on explants of all cultivars continued to elongate after the data were collected, but the ranking was not altered (data not shown).

Rooting. Cuttings of shoots rooted easily (within $15 \mathrm{~d}$ ) in both basal medium and sphagnum moss. Root initiation was observed with a few cuttings after $7 \mathrm{~d}$ of culture in the sphagnum moss and $1 \mathrm{~d}$ later in the basal medium. All of the cuttings rooted in the moss medium within $15 \mathrm{~d}$. The rooting response was similar on the basal medium, but roots in the sphagnum moss appeared to be more vigorous. Most roots were generated near the basal cut surface, but also occurred higher on the stem and from the leaf axils. No obvious callus formed on the cut surface.

\section{Discussion}

A number of factors affect adventitious shoot regeneration from tissue-cultured explants such as genotype, culture medium (including growth regulators and their combinations), physical environment, explant developmental stage, etc. For a particular species, culture medium, and, especially, growth regulators and their combinations, appear to be the most important factors. While 2ip is an effective stimulus in regeneration of blueberry (Vaccinium corymbosum L.) from leaf tissue (Billings et al., 1988; Callow et al., 1989; Dweikat and Lyrene, 1988; Rowland and Ogden, 1992), it either produces a low rate of regeneration in cranberry leaves when used in combination with NAA (Scorza and Welker, 1988), or fails to induce regeneration when used alone (Marcotrigiano et al., 1996). With the inclusion of TDZ, which is possibly the most potent cytokinin for woody plant tissue culture (Huetteman and Preece, 1993; Mok et al., 1987), shoot regeneration is achieved from in vitro cranberry stem sections (Serres and McCown, 1995) and leaves (Marcotrigiano et al., 1996). However, the regeneration efficiency is between five and nine buds per stem explant (Serres and McCown, 1995), or was considered far less than that desired for purposes of micropropagation or transformation when using leaf explants (Marcotrigiano et al., 1996). Elongation of the shoot meristems in cranberry is very difficult to induce (Marcotrigiano et al., 1996). The series of experiments presented herein demonstrate that we have achieved a very efficient organogenesis (shoot regeneration) system from cranberry leaves using a combination of TDZ and 2ip and eliminating auxin (i.e., NAA) from the regeneration medium. Other aspects in the system, such as shoot meristem elongation and rooting efficiency, have also been significantly improved.

Comparing our system to previous cranberry regeneration studies (Marcotrigiano et al., 1996; Scorza and Welker, 1988; Serres et al., 1992), several factors emerge that significantly affect regeneration. These factors are the nature and concentration of growth regulators, the genotype, and the orientation of the explants on the medium. The ingredients and the $\mathrm{pH}$ of the basal medium may also have an influence.

Enhancement of axillary shoot proliferation from woody plants in vitro by combinations of TDZ and other cytokinin-like compounds has been observed in Acer $\times$ fremanii (Kerns and Meyer, 1987), Pyrus communis L. (Singha and Bhatia, 1988), Fraxinus americana L. (Navarrete et al., 1989), and Vitis rotundifolia Michx. (Sudarsono and Goldy, 1991). Effectiveness of combinations of cytokinin-like compounds, including TDZ, have been reported for in vitro regeneration studies (Ellis et al., 1991; Serres et al., 1992). The benefits of using a combination of cytokinins, rather than a single compound, may be an indication of differences in uptake, recognition by the cells, or mechanisms of action of the compounds (Huetteman and Preece, 1993). Although Marcotrigiano et al.(1996) failed to induce regeneration of shoots from cranberry leaves using 2ip alone, results with cranberry leaves (Scorza and Welker, 1988) and stem sections (Serres et al., 1992), using 2ip in combination with other growth regulators, suggest that 2ip may have potential in promoting shoot regeneration. Our experiments show that when TDZ is combined with 2ip at particular concentrations, enhanced adventitious shoot regeneration can be achieved in cranberry.

Combinations of high levels of cytokinin and low levels of auxin stimulate shoot proliferation and organogenesis in tissue culture (Fasolo et al., 1989; Marcotrigiano et al., 1996). However, we found that even a very low level $(0.1 \mu \mathrm{M})$ of NAA significantly reduced regeneration efficiency from cranberry leaves. Efficient regeneration can be achieved using $10 \mu \mathrm{M}$ TDZ alone without supplemental auxin. Negative effects of NAA on regeneration efficiency have been reported in Citrullus colocynthis L. (Dabauza et al., 1997), a watermelon cultivar (Compton and Gray, 1993; Srivastava et al., 1989) and blueberry (Billings et al., 1988), a close relative of cranberry. The report (Marcotrigiano et al., 1996) that the maximum regeneration efficiency from cranberry is achieved on a high concentration of NAA (10.0 $\mu \mathrm{M}$ TDZ and $1.0 \mu \mathrm{M}$ NAA) conflicts with our results. Genotypic differences, medium composition, $\mathrm{pH}$ and other unrecognized differences in the culture methods might explain this discrepancy. A high NAA concentration promotes callus production and reduces shoot formation in watermelon (Compton and Gray, 1993) and blueberry (Billings et al., 1988), these results resemble ours.

The same macro salts (Anderson, 1975) were used in our basal medium and that of Marcotrigiano et al. (1996). We also used 
Anderson's micro salts, while Marcotrigiano et al. (1996) used Murashige and Skoog's (1962) micro salts. There are only quantitative differences in three compounds between the two sources of micro salts [Na-EDTA, ferrous sulfate, $7 \mathrm{H}_{2} \mathrm{O}$, and potassium iodide $(74.5$, 55.7 , and $0.3 \mathrm{mg} \cdot \mathrm{L}^{-1}$, respectively, in Anderson's, and 37.26, 27.8, and 0.83, respectively, in Murashige and Skoog's)]. These differences in concentrations may contribute to the differences in regeneration rates.

Another difference between the studies is the $\mathrm{pH}$, which was adjusted to 5.3 in our medium, while Marcotrigiano et al. (1996) used 4.5. We chose the higher $\mathrm{pH}$ because we plan to examine the potential for efficient transformation of cranberry by Agrobacterium, which has a functional $\mathrm{pH}$ optimum around this value (5.3) (Winans et al., 1988).

In blueberry, both abaxial side down (Callow et al., 1989; Shibli and Smith, 1996) and up (Billings et al., 1988; Rowland and Ogden, 1992) are used in leaf regeneration, although Billings et al. (1988) reported that shoots originate only from the abaxial side. However, orientation of leaf explants with the abaxial side in contact with medium enhanced regeneration in cranberry. Shoot regeneration occurred almost exclusively on the adaxial side for all genotypes tested in our study, although Marcotrigiano et al. (1996) reported that shoot regeneration occurred on both sides of the leaves. As with differences in regeneration efficiency, genotypic or other differences, such as medium composition and $\mathrm{pH}$, may explain the observed variation.

The lack of cultivar $\times$ growth regulator interaction and consistent differences among cultivars in performance across experiments suggest that regeneration capacity is genetically controlled and that the mechanism of regeneration is similar across genotypes. Note that very good regeneration was also observed with stem sections of all genotypes in this study when $10.0 \mu_{\mathrm{M}} \mathrm{TDZ}$ with $5.0 \mu_{\mathrm{M}} 2 \mathrm{ip}$ were used (data not shown).

Inhibition of elongation of shoot meristems generated on TDZ-containing medium has been reported in several woody species (reviewed by Huetteman and Preece, 1993) and in cranberry (Marcotrigiano et al., 1996). Huetteman and Preece (1993) suggested that this is caused by the high cytokinin activity of TDZ rather than being toxic effect. However, Ellis et al. (1991) observed better elongation of adventitious shoots of white spruce [Picea glauca (Moench) Voss.] when TDZ was combined with other cytokinins (BA or zeatin) than when using the latter compounds alone. Inclusion of 2ip in the culture medium and transfer of explants to low TDZ medium (after initiation of regeneration in the high TDZ medium) resulted in enhanced elongation efficiency in our system.

Aging of explants generally has a significant negative effect on regeneration (Pierik, 1987). Fasolo et al. (1989) found that leaf position in apple (Malus $\times$ domestica Borkh.) had a significant effect on regeneration, and only a few apical leaves were used by Hammerschlag et al. (1997) for regeneration of this species. For plants with small leaves, such as cranberry, material for large-scale experiments can become limiting if only a few apical leaves are suitable for regeneration. No information was provided on leaf age (position) effects in previous cranberry regeneration studies (Marcotrigiano et al., 1996; Scorza and Welker, 1988). The finding that efficient regeneration can be achieved by using more than the apical 10 leaves of a cranberry shoot grown in vitro is encouraging information for large scale experiments.

In conclusion, we have established a very efficient regeneration system for cranberry leaves. This system uses a basal medium supplemented with $10 \mu \mathrm{M}$ TDZ and $5.0 \mu \mathrm{M} 2 \mathrm{ip}$, followed by transfer to fresh medium containing $1.0 \mu \mathrm{M}$ TDZ and $10.0 \mu \mathrm{M} 2 \mathrm{ip}$, and, finally, to growth regulator-free medium for shoot elongation. The high regeneration efficiency achieved using this system will be very useful in the application of transformation techniques for cranberry, including both Agrobacteriumand particle bombardment-mediated transformation. Since shoots were regenerated directly from leaf tissue, this system is less likely to result in somaclonal variation, and therefore should be ideal for rapid micropropagation of valuable cranberry genotypes, such as elite wild and breeding selections.

\section{Literature Cited}

Ahuja, S., B. Kaak, and J. Roberts. 1998. Loss of fimbrial adhesion with the addition of Vaccinium macrocarpon to the growth medium of $\mathrm{P}$ fimbriated Escherichia coli. J. Urology 159:559562

Anderson, W.C. 1975. Propagation of rhododendrons by tissue culture. Part 1. Development of a culture medium for multiplication of shoots. Proc. Intl. Plant Prop. Soc. 25:129-134.

Billings, S.G., C.K. Chin, and G. Jelenkovic. 1988. Regeneration of blueberry plantlets from leaf segments. HortScience 23:763-766.

Callow, P., K. Haghighi, M. Giroux, and J. Hancock. 1989. In vitro shoot regeneration on leaf tissue from micropropagated highbush blueberry. HortScience 24:373-375.

Dabauza, M., M. Bordas, A. Salvador, L.A. Roig, and V. Moreno. 1997. Plant regeneration and Agrobacterium-mediated transformation of cotyledon explants Citrillus colocynthis (L.) Schrad. Plant Cell Rpt. 16:888-892.

Dweikat, I.M. and P.M. Lyrene. 1988. Adventitious shoot production from leaves of blueberry cultivated in vitro. HortScience 23:629.

Eck, P. 1990. The American cranberry. Rutgers Univ. Press, New Brunswick and London.

Ellis, D.D., H. Barczynska, B.H. McCown, and N. Nelson. 1991. Comparison of BA, zeatin, and thidiazuron for adventitious bud formation from Picea glauca embryos and epicotyl explants. Plant Cell Tiss. Organ Cult. 27:281-287.

Fasolo, F., R.H.Zimmerman, and I. Fordham. 1989 Adventitious shoot formation on excised leaves of in vitro grown shoots of apple cultivars. Plant Cell Tiss. Organ Cult. 16:75-87.

Hammerschlag, F.A., R.H. Zimmerman, U.L. Yadava, S. Hunsucker, and P. Gercheva. 1997. Effect of antibiotics and exposure to an acidified medium on the elimination of Agrobacterium tumefaciens from apple leaf explants and on shoot regeneration. J. Amer. Soc. Hort. Sci. 122:758-763.

Howell, A.B., N. Vorsa, A.D. Marderosian, and L.Y.Foo. 1998. Inhibition of the adherence of Pfimbriated Escherichia coli to uroepithelial-cell surfaces by proanthocyanadin extracts from cranberries. New England J. Med. 339:1085-1086.

Huetteman, C.A. and J.E. Preece. 1993. Thidiazuron: A potent cytokinin for woody plant tissue culture. Plant Cell Tiss. Organ Cult. 33:105-119.

Kerns, H.R. and M. M. Meyer. 1987. Diligence finds the chemical key to micropropagating a new maple. Amer. Nurseryman 165:104-110.

Marcotrigiano, M., S.P. McGlew, G. Hackett, and B. Chawla. 1996. Shoot regeneration from tissue-cultured leaves of the American cranberry (Vaccinium macrocarpon). Plant Cell Tiss. Organ Cult. 44:195-199.

Mok, M.C., D.W.S. Mok, J.E. Turner, and C.V. Mujer. 1987. Biological and biochemical effects of cytokinin-active phenylurea derivatives in tissue culture systems. HortScience 22:1194 1197.

Murashige, T. andF. Skoog. 1962. A revised medium for rapid growth and bioassays with tobacco tissue cultures. Physiol. Plant. 15:473-479.

Navarrete, N.E., J.W.V. Sambeek, J. E. Preece, and G. R. Gaffney. 1989. Improved micropropagation of white ash (Fraxinus americana L.), p. 146-149. In: Proc. 7th Central Hardwood Forest Conf., Carbondale, Ill.

Ofek, I., J. Goldhar, D. Zafriri, H. Lis, R. Adar, and N. Sharon. 1991. Anti-Escherichia coli adhesion activity of cranberry and blueberry juices. New England J. Med. 324:1599.

Pierik, R.L.M. 1987. In vitro culture of higher plants. Martinus Nijhoff, Dordrecht, The Netherlands.

Rowland, L.J. and E.L. Ogden. 1992. Use of a cytokinin conjugate for efficient shoot regeneration from leaf sections of highbush blueberry. HortScience 27:1127-1129.

Scorza, R. and W.V. Welker. 1988. Cranberries (Vaccinium macrocarpon Ait.), p. 199-209. In: Y.P.S. Bajaj (ed.). Biotechnology in agriculture and forestry. vol. 6. Crops II. Springer-Verlag, Berlin.

Serres, R., E. Stang, D. McCabe, D. Russell, D. Mahr, and B. McCown. 1992. Gene transfer using electric discharge particle bombardment and recovery of transformed cranberry plants. J. Amer. Soc. Hort. Sci. 117:174-180.

Serres, R.A. and B.H. McCown. 1995. Genetic transformation in Vaccinium macrocarpon Ait. (cranberry), p. 299-308. In: Y.P.S. Bajaj (ed.). Biotechnology in agriculture and forestry. vol. 34, Springer-Verlag, Berlin.

Shibli, R. and M.A.L. Smith. 1996. Direct shoot regeneration from Vaccinium pahalae (Ohelo) (Bilberry) leaf explants. HortScience 31:12251228

Singha, S. and S.K. Bhatia. 1988. Shoot proliferation of pear cultures on medium containing thidiazuron and benzylamino purine. HortScience 23:803 (Abstr.)

Srivastava, D.R., V.M. Andrianov, andE.S. Piruzian. 1989. Tissue culture and plant regeneration of watermelon (Citrullus vulgaris Schrad. cv. Melitopolski). Plant Cell Rpt. 8:300-302.

Sudarsono and R.G. Goldy. 1991. Growth regulator and axillary bud position effects on in vitro establishment of Vitis rotundifolia. HortScience 26:304-307.

Winans, S.C., R.A. Kerstetter, and E.W. Nester. 1988. Transcription regulation of the virA and virG genes of Agrobacterium tumefaciens. J. Bacteriol. 170:4047-4054. 